University of South Carolina

Scholar Commons

Faculty Publications

Mathematics, Department of

$12-1972$

\title{
Nonnegative matrices whose inverses are M-matrices
}

Thomas L. Markham

University of South Carolina - Columbia, markham@math.sc.edu

Follow this and additional works at: https://scholarcommons.sc.edu/math_facpub

Part of the Mathematics Commons

\section{Publication Info}

Proceedings of the American Mathematical Society, Volume 36, Issue 2, 1972, pages 326-330.

(C) 1972 by American Mathematical Society

This Article is brought to you by the Mathematics, Department of at Scholar Commons. It has been accepted for inclusion in Faculty Publications by an authorized administrator of Scholar Commons. For more information, please contact digres@mailbox.sc.edu. 


\title{
NONNEGATIVE MATRICES WHOSE INVERSES ARE $M$-MATRICES
}

\author{
THOMAS L. MARKHAM
}

\begin{abstract}
A characterization of a class of totally nonnegative matrices whose inverses are $M$-matrices is given. It is then shown that if $A$ is nonnegative of order $n$ and $A^{-1}$ is an $M$-matrix, then the almost principal minors of $A$ of all orders are nonnegative.
\end{abstract}

I. Introduction. Suppose $A=\left(a_{i j}\right)$ is a matrix of order $n$. We write $A \geqq 0$ if $a_{i j} \geqq 0$ for each pair $(i, j), A$ is called totally nonnegative (totally positive) if all minors of all orders of $A$ are nonnegative (positive). Finally, if $A$ is totally nonnegative, and a power of $A$ is totally positive, then $A$ is said to be oscillatory (see [2], [3] for pertinent results).

Fiedler and Pták gave the following characterization of $M$-matrices in [1], which we shall use as a definition.

Definition 1.1. Suppose $A$ is a real $n \times n$ matrix with nonpositive offdiagonal elements. Then $A$ is an $M$-matrix if and only if $A$ is nonsingular and $A^{-1} \geqq 0$.

In $\S \mathrm{II}$, we offer a characterization of a class of totally nonnegative matrices whose inverses are $M$-matrices. We prove in §III that if $A \geqq 0$ and $A^{-1}$ is an $M$-matrix, then the almost principal minors of $A$ of all orders are nonnegative.

II. $A \geqq 0$ with $A$ totally nonnegative. All matrices considered are of order $n$. Let $A_{i, j}$ be the submatrix of $A$ of order $n-1$ obtained by deleting row $i$ and column $j$.

THEOREM 2.1. Suppose $A$ is a nonsingular, totally nonnegative matrix. Then $A^{-1}$ is an M-matrix if and only if $\operatorname{det}\left(A_{i, j}\right)=0$ for $i+j=2 K$, where $K$ is a positive integer, and $i \neq j$.

Proof. Suppose $A^{-1}=\left(\alpha_{i j}\right)$ is an $M$-matrix. Then $\alpha_{i j} \leqq 0$ for $i \neq j$. But $\alpha_{i j}=\left[(-1)^{i+j} \operatorname{det}\left(A_{j, i}\right)\right] / \operatorname{det}(A)$. Since $A$ is totally nonnegative, we have $\operatorname{det}\left(A_{j, i}\right) \geqq 0$ and $A$ nonsingular implies $\operatorname{det}(A)>0$. Thus we have $\operatorname{det}\left(A_{j, i}\right)=0$ for $i+j=2 K$ and $i \neq j$.

Received by the editors January 3, 1972.

AMS 1970 subject classifications. Primary 15-00.

Key words and phrases. Nonnegative matrix, totally nonnegative matrix, $M$-matrix, almost principal minor.

(c) American Mathematical Society 1973 
If $\operatorname{det}\left(A_{j, i}\right)=0$ for $i+j=2 K$ and $i \neq j$, then clearly $\alpha_{i j} \leqq 0$ for $i \neq j$. The fact that $A^{-1}$ is an $M$-matrix now follows from Definition 1.1.

Next, we examine a special class of oscillatory matrices with the property that each element has an $M$-matrix as its inverse. We call $A=\left(a_{i j}\right)$ a matrix of type $D$ if

$$
a_{i j}=\left\{\begin{array}{ll}
a_{i}, & i \leqq j, \\
a_{j}, & i>j,
\end{array} \text { where } a_{n}>a_{n-1}>\cdots>a_{1} .\right.
$$

It was shown by the author in [3] that $a_{1}>0$, then a matrix of type $D$ is oscillatory.

Theorem 2.2. Suppose $A$ is a matrix of type $D$ with $a_{11}>0$. Then $\operatorname{det}\left(A_{i, j}\right)=0$ for $|i-j|>1$.

Proof. Since $A$ is symmetric, we shall assume $j>i+1$. If $i=1$, then the second column of $A_{i, j}$ is a multiple of the first column and $\operatorname{det}\left(A_{i, j}\right)=0$. If $j=n$, then the last two rows of $A_{i, n}$ are identical and $\operatorname{det}\left(A_{i, n}\right)=0$. We assume $i \neq 1$ and $j \neq n$. Let

$$
\operatorname{det}\left(A_{i, j}\right)=\operatorname{det}\left(\begin{array}{ll}
B_{1} & B_{2} \\
B_{3} & B_{4}
\end{array}\right),
$$

where $B_{1}$ is $(i-1) \times(i+1)$ and $B_{4}$ is of order $(n-i) \times(n-i-2)$. (Note that $n \geqq 4$ here.) Using the Laplace expansion for $\operatorname{det}\left(A_{i, j}\right)$ and expanding by the last $n-i$ rows of $A_{i, j}$, we see that 2 columns must always be chosen from $B_{3}$ since $B_{4}$ contains only $n-i-2$ columns. But in $B_{3}$ all columns are multiples of the first column. Thus in the sum of the determinants in the Laplace expansion, each term is zero, and hence $\operatorname{det}\left(A_{i, j}\right)=0$. The proof is complete.

THEOREM 2.3. Suppose $A=\left(a_{i j}\right)$ is a matrix of type $D$ with $a_{11}>0$. Then $A^{-1}$ is a tridiagonal M-matrix.

Proof. $\quad A^{-1}$ is tridiagonal, since $\operatorname{det}\left(A_{i, j}\right)=0$ for $|i-j|>1$, and $A^{-1}$ is an $M$-matrix by Theorem 2.1 and Definition 1.1.

III. Nonnegativity of almost principal minors of matrices whose inverses are $M$-matrices. Gantmacher and Kreĭn defined the term almost principal minor in their study of totally nonnegative matrices [2]. We shall use the following definition: If $\alpha$ and $\beta$ are strictly increasing sequences on $N=\{1, \cdots, n\}$ of the same length, then $A(\alpha \mid \beta)$ is the minor of $A$ with rows indexed by $\alpha$ and columns indexed by $\beta$. We say that $A(\alpha \mid \beta)$ is an almost principal minor of $A$ if in the sequence $|\alpha-\beta|=\left(\left|\alpha_{1}-\beta_{1}\right|, \cdots,\left|\alpha_{K}-\beta_{K}\right|\right)$ exactly one term is nonzero. 
Our main result is the

THEOREM 3.1. If $A \geqq 0$ and $A^{-1}$ is an M-matrix, then the almost principal minors of $A$ are nonnegative.

First, we prove the

Lemma. If

$$
A=\left(\begin{array}{ll}
A_{11} & A_{12} \\
A_{21} & a_{n n}
\end{array}\right) \geqq 0
$$

where $A_{11}$ is of order $n-1$, and if $A^{-1}$ is an M-matrix, then $A_{11}^{-1}$ exists and is an M-matrix.

Proof. To demonstrate that $A_{11}$ is nonsingular, we partition $A^{-\mathbf{i}}$ conformably with $A$ as

$$
A^{-1}=\left(\begin{array}{ll}
B_{11} & B_{12} \\
B_{21} & b_{n n}
\end{array}\right)=\left(b_{i j}\right)
$$

Immediately we obtain the relation

$$
A_{11} B_{11}+A_{12} B_{21}=I .
$$

Since $A_{12} B_{21}$ is of rank at most one, its characteristic polynomial is

$$
\begin{aligned}
p(m) & =\operatorname{det}\left[m I-A_{21} B_{21}\right] \\
& =m^{n-1}-\left[\operatorname{trace}\left(A_{12} B_{21}\right)\right] m^{n-2} .
\end{aligned}
$$

Thus $p(1)=\operatorname{det}\left(I-A_{12} B_{21}\right)=1+\sum_{i=1}^{n-1} a_{i n}\left|b_{n i}\right| \geqq 1$. This implies that $A_{11} B_{11}$ is nonsingular. Thus both $A_{11}$ and $B_{11}$ are nonsingular, and from (1), we get

$$
A_{11}^{-1}=B_{11}\left(I-A_{12} B_{21}\right)^{-1} .
$$

We show next that $C=\left(I-A_{12} B_{21}\right)^{-1}$ is an $M$-matrix, and finally that $B_{11} C$ is an $M$-matrix.

It is easy to verify that $C=\left(c_{i j}\right)$ where

$$
\begin{gathered}
c_{\imath i}=\left(1+\sum_{j \neq i} a_{\jmath n}\left|b_{n j}\right|\right) / \operatorname{det}\left(I-A_{12} B_{21}\right) \text { for all } i, \\
c_{\imath j}=a_{i n} b_{n j} / \operatorname{det}\left(I-A_{12} B_{21}\right) \quad \text { for } i \neq j .
\end{gathered}
$$

Hence $C$ has nonpositive off-diagonal elements, and $C^{-1}=\left(I-A_{12} B_{21}\right) \geqq 0$. So $C$ is an $M$-matrix. Also, $B_{11}$ is an $M$-matrix since $A^{-1}$ is an $M$-matrix. 
Let $d=\operatorname{det}\left(I-A_{12} B_{21}\right)$. For $i \neq j$, we have

$$
\begin{aligned}
\left(A_{11}^{-1}\right)_{i, j} & =\sum_{k=1}^{n-1} b_{i k} c_{k j} \\
& =\frac{1}{d}\left\{\sum_{k \neq j} b_{\imath k} a_{k n} b_{n j}+b_{i j}\left(1+\sum_{p \neq j} a_{p n}\left|b_{n p}\right|\right)\right\} \\
& =\frac{b_{n j}}{d}\left(\sum_{k \neq j}^{n-1} b_{\imath k} a_{k n}\right)+\frac{b_{\imath j}}{d}\left(1+\sum_{p \neq j}^{n-1} a_{p n}\left|b_{n p}\right|\right) .
\end{aligned}
$$

From $B A=I$, we obtain $\sum_{k \neq j}^{n-1} b_{i k} a_{k n}=-b_{i j} a_{j n}-b_{i n} a_{n n} \geqq 0$, and so $\left(A_{11}^{-1}\right)_{i, j} \leqq 0$ for $i \neq j . A_{11}^{-1}$ is an $M$-matrix since $A_{11} \geqq 0$, and the lemma is proved.

There is nothing special about the fact that $A_{11}$ is contained in consecutive rows and columns $1,2, \cdots, n-1$. For if $E$ is a principal submatrix of $A \geqq 0$ of order $n-1$, we can simultaneously permute rows and columns of $A$ such that

$$
P A P^{T}=\left(\begin{array}{ll}
E & E_{12} \\
E_{21} & e_{n n}
\end{array}\right)
$$

and $P A P^{T} \geqq 0$. It is clear that if $A^{-1}$ is an $M$-matrix, then $P A^{-1} P^{T}$ is an $M$-matrix by Definition 1.1. Hence we state the

Corollary. If $A \geqq 0$ and $A^{-1}$ is an $M$-matrix and if $S$ is a principal submatrix of $A$ of order $n-1$, then $S^{-1}$ exists and is an $M$-matrix.

We return to the proof of Theorem 3.1.

The almost principal minors of $A$ of order $n-1$ are nonnegative since $b_{\imath, i+1} \leqq 0$ and $b_{\imath+1, \imath} \leqq 0$ for $i=1, \cdots, n-1$, i.e. $\operatorname{det}\left(A_{i, \imath+1}\right) \geqq 0$ and $\operatorname{det}\left(A_{i+1, i}\right) \geqq 0$ for $i=1, \cdots, n-1$, and these exhaust the almost principal minors of order $n-1$.

Any almost principal minor of order $n-2$ or less is contained in a principal submatrix, $S$, of $A$ of order $n-1$. The proof is completed by using induction.

The condition of Theorem 3.1 is not sufficient for $A^{-1}$ to be an $M$ matrix. Suppose

$$
A=\left(\begin{array}{lll}
1 & 1 & 1 \\
1 & 2 & 3 \\
1 & 3 & 6
\end{array}\right) \text {. }
$$

Then $A \geqq 0$ and the almost principal minors of $A$ are nonnegative. In fact, $A$ is oscillatory. $A^{-1}$ is not an $M$-matrix since $\operatorname{det}\left(A_{3,1}\right)=1$ and Theorem 2.1 does not hold. 
The author would like to express his appreciation to Miroslav Fiedler for helpful comments concerning the topics of $\S I I I$, and to the referee for several comments which helped to improve the exposition.

\section{REFERENCES}

1. M. Fiedler and V. Pták, On matrices with non-positive off-diagonal elements and positive principal minors, Czechoslovak Math. J. 12 (87) (1962), 382-400. MR 26 \#134.

2. F. R. Gantmacher and M. G. Kreĭn, Sur les matrices complétement non-negatives et oscillatories, Compositio Math. 4 (1937), 445-476.

3. T. L. Markham, On oscillatory matrices, Linear Algebra and Appl. 3 (1970), 143-156. MR 41 \#5392.

Department of Mathematics, University of South Carolina, Columbia, South CAROLINA 29208 